\title{
Efeitos do tipo de bebedouro sobre a qualidade da água e o desempenho e a qualidade dos ovos de poedeiras comerciais
}

\section{Cristina Kimie Togashi ${ }^{1}$, Henrique Lopes da Angela ${ }^{2}$, Ednardo Rodrigues Freitas ${ }^{3}$, Elisabete Aparecida Lopes Guastalli ${ }^{4}$, Marcos Roberto Buim ${ }^{4}$, Nilce Maria Soares Queiroz Gama ${ }^{4}$}

\author{
${ }^{1}$ APTA Alta Paulista, Adamantina-SP \\ 2 Médico Veterinário. \\ 3 Universidade Federal do Ceará. \\ 4 IB/CAPTAA/ULPA, Bastos-SP.
}

RESUMO - Um experimento foi realizado para avaliar os efeitos da forma de fornecimento de água sobre o desempenho e a qualidade de ovos de poedeiras comerciais. Utilizaram-se 100 poedeiras comerciais com 44 semanas de idade distribuídas em um delineamento inteiramente casualizado com dois tratamentos (tipos de bebedouros: taça e nipple), cada um com dez repetições de cinco aves. O experimento foi conduzido durante 63 dias, divididos em três períodos de 21 dias. As aves que utilizaram bebedouro tipo nipple apresentaram maior porcentagem de postura e melhor conversão alimentar. A qualidade dos ovos não foi influenciada pelo tipo de bebedouro utilizado. O uso de bebedouro tipo nipple possibilita o fornecimento de água com melhor qualidade microbiológica para as poedeiras e, conseqüentemente, favorece o desempenho das aves.

Palavras-chave: avicultura, desempenho, nipple, taça

\section{Effect of the drinking system on water quality and laying hen performance and egg quality}

\begin{abstract}
An experiment was carried out to evaluate the effect of different forms of water supply for laying hens on performance and egg and water quality. Two types of drinking system were evaluated: cup and nipple. In each treatment 10 replicates had been used, composed for five hens. The experiment lasted 63 days, divided in three periods of 21 days. Data of performance and egg quality were submitted to variance analysis and, when the differences were significant, they were compared by F test. Data of microbiological quality were compared by qui-square test. Hens submitted to nipple drinking system showed greater egg production and better feed conversion. No treatment differences on egg quality were detected. However, in the evaluations of the water bacteriological quality it was evident that the nipple drinking system provides better water quality and performance of laying hens
\end{abstract}

Key Words: aviculture, cup, nipple, performance

\section{Introdução}

A água representa de 55 a 75\% do conteúdo corporal das galinhas e aproximadamente 65\% do ovo (Koelkebeck et al., 1999). Uma ave pode sobreviver até 30 dias sem alimento, no entanto, morre quando perde $20 \%$ da água presente em seu organismo (Vohra, 1980).

$\mathrm{Na}$ avicultura industrial, é fundamental o uso racional de água de boa qualidade. O uso de água de qualidade duvidosa pode prejudicar os índices zootécnicos (Tabler, 2003), promover a disseminação de enfermidades que acarretam graves prejuízos econômicos (Gama, 2005), além de carrear agentes patogênicos causadores de enfermidades de interesse na área de saúde pública (Barros et al., 2001).
A indústria de equipamentos avícolas desenvolveu-se muito nos últimos anos. Entre os tipos de bebedouros disponíveis no mercado para aves de postura, destacam-se os tipos chupeta (nipple) e taça. Em estudos sobre bebedouros, há informações sobre a qualidade microbiológica e a incidência de doenças na avicultura (Amaral et al., 2001; Barros et al., 2001; Valias \& Silva 2001; Amaral, 2004) ou sobre o manejo dos equipamentos (Ramos et al., 1990; Gernat \& Adams, 1990, 1992), mas ainda há carência de estudos para avaliação da influência do tipo de bebedouro sobre o desempenho das aves e a qualidade da água ingerida.

Este estudo foi realizado com o objetivo de verificar os efeitos da utilização de dois tipos de bebedouro sobre a qualidade da água ingerida e sobre o desempenho e a qualidade dos ovos de poedeiras comerciais. 


\section{Material e Métodos}

O experimento foi realizado na Instalação Experimental da Unidade Laboratorial de Patologia Avícola/CAAPTA/ IB. Bastos, SP. Foram utilizadas 100 poedeiras comerciais Bovans White com 44 semanas de idade, alojadas em galpão coberto com telhas de barro, telado lateralmente e dotado de gaiolas de arame galvanizado (50 cm de largura $\times 44 \mathrm{~cm}$ de comprimento $\times 44 \mathrm{~cm}$ de altura) equipadas com comedouro do tipo calha e com os bebedouros em estudo. As aves foram pesadas $(1.410 \pm 110,9 \mathrm{~g})$ e distribuídas em delineamento inteiramente casualizado, com dois tratamentos e dez repetições de cinco aves. Os tratamentos consistiram no fornecimento da água de dessedentação com uso do bebedouro tipo taça ou bebedouro tipo nipple. Os bebedouros nipple utilizados foram da marca Lubing ${ }^{\circledR}$.

O experimento foi realizado após um período de adaptação de dez dias, nos meses de dezembro de 2006 a fevereiro de 2007 e teve duração de 63 dias, divididos em três períodos de 21 dias. Durante todo o experimento, as aves receberam ração e água à vontade e foram submetidas a um programa com 16 horas de luz por dia (natural + artificial). As aves dos dois tratamentos receberam a mesma ração comercial, à base de milho e farelo de soja (2.750 kcal de energia metabolizável/kg; 17,5\% de proteína bruta; 4,0\% de cálcio e $0,45 \%$ de fósforo disponível).

A água fornecida às aves foi previamente filtrada e armazenada em caixas d'água individualizadas para cada tratamento. Em virtude da impossibilidade de se medir o consumo de água por parcela, diariamente foram anotados os dados referentes ao consumo e à temperatura de água em cada tipo de bebedouro.

A quantidade de água consumida foi obtida pela diferença entre a quantidade de água fornecida e a sobra nas caixas. A temperatura da água foi medida diariamente no final da tarde, por volta das $16 \mathrm{~h}$, por meio da coleta de amostras obtidas em diversos pontos das linhas de água e com o uso de termômetro. Também foram registradas as temperaturas máxima e mínima do galpão de criação durante todo o período experimental.

Como características de desempenho, avaliaram-se o consumo de ração (g/ave/dia), a porcentagem de postura (ave/dia), a massa de ovo (g/ave/dia) e a conversão alimentar (kg de ração/kg de ovo). As avaliações da qualidade dos ovos foram realizadas nos três últimos dias de cada período. Os ovos de cada repetição foram coletados e identificados para determinação do peso médio (g), da gravidade específica e da porcentagem de casca.
Os ovos de cada parcela foram pesados e posteriormente utilizados na avaliação da gravidade específica, realizada pelo método de flutuação do ovo em soluções salinas com concentrações de 1,062 a 1,098, com intervalos de 0,004 . Em seguida, os ovos foram quebrados para coleta das cascas, que, depois de retiradas, foram lavadas e secas à sombra por 48 horas para pesagem. A porcentagem de casca foi determinada pela relação entre o peso da casca e o peso do ovo.

A qualidade bacteriológica da água foi avaliada pela contagem dos coliformes totais e fecais presentes nas amostras de água, segundo metodologia descrita na instrução Normativa $N^{\circ} 62$ (Brasil, 2003). Semanalmente, foram realizadas coletas de água nos bebedouros nipple, pressionando-se a válvula do bebedouro com uma espátula esterilizada, produzindo um fluxo de água diretamente para o frasco de coleta. Nos bebedouros do tipo taça, a amostra de água foi coletada com o auxílio de uma seringa esterilizada, diretamente do copo receptor, e armazenada em frasco esterilizado.

A análise estatística foi realizada utilizando-se o programa Statistical Analisys System (SAS $\left.{ }^{\circledR}, 2001\right)$. Os dados de desempenho e qualidade dos ovos foram submetidos à análise de variância pelo procedimento ANOVA e a diferença entre os tipos de bebedouro foi obtida pelo teste $\mathrm{F}(\mathrm{P}<0,05)$.

Os dados semanais obtidos foram analisados pelo procedimento PROC COR para verificar possíveis associações entre temperatura ambiente $\left({ }^{\circ} \mathrm{C}\right)$, temperatura da água, consumos de água (mL/ave/dia) e de ração (g/ave/dia) e tipo bebedouro. Na avaliação da qualidade da água, a incidência de amostras com concentrações $>11.000$ Número Mais Provável (NMP)/100 mL e $<3$ para coliformes fecais e totais entre os tipos de bebedouro foi comparada pelo teste do qui-quadrado $(\mathrm{P}<0,05)$ utilizando-se os dados de todas as coletas.

\section{Resultados e Discussão}

A temperatura ambiente teve correlação $(\mathrm{P}<0,05)$ com a temperatura da água do bebedouro $(\mathrm{r}=0,84)$, com o consumo de água $(r=0,89)$ e com o consumo de ração $(r=-0,79)$ (Tabela 1). Também foram verificadas correlações $(\mathrm{P}<0,05)$ entre a temperatura da água e os consumos de água $(\mathrm{r}=0,60)$ e de ração $(r=-0,67)$ e entre o consumo de água e o consumo de ração $(r=-0,51)$.

A ingestão de água pelas aves é regulada por vários fatores, como temperatura ambiente e da água, ingestão de alimento, composição da dieta, idade da ave, entre outros (Leeson \& Summers, 1997; Fairchild \& Ritz, 2006). Quando 
Tabela 1 - Médias semanais de temperatura ambiente, temperatura da água, consumo de água e consumo de ração em poedeiras criadas com dois tipos de bebedouro

\begin{tabular}{|c|c|c|c|c|c|c|c|c|}
\hline \multirow[t]{2}{*}{ Semana } & \multicolumn{2}{|c|}{ Temperatura ambiente } & \multicolumn{2}{|c|}{ Temperatura da água } & \multicolumn{2}{|c|}{ Consumo de água (mL/ave/dia) } & \multicolumn{2}{|c|}{ Consumo de ração (g/ave/dia) } \\
\hline & Máxima & Mínima & Taça & Nipple & Taça & Nipple & Taça & Nipple \\
\hline 1 & 30,90 & 21,90 & $*$ & $*$ & 241,00 & 210,00 & 96,46 & 99,46 \\
\hline 2 & 34,60 & 24,70 & 34,00 & 33,50 & 255,00 & 215,00 & 94,26 & 97,77 \\
\hline 3 & 30,50 & 22,60 & 32,00 & 31,00 & 224,00 & 191,00 & 110,37 & 109,11 \\
\hline 4 & 30,40 & 23,20 & 30,30 & 29,60 & 232,00 & 190,00 & 105,60 & 110,63 \\
\hline 5 & 29,20 & 23,50 & 30,20 & 29,60 & 220,00 & 198,00 & 112,77 & 113,60 \\
\hline 6 & 31,60 & 23,50 & 32,10 & 31,20 & 232,00 & 185,00 & 99,11 & 102,00 \\
\hline 7 & 31,70 & 22,80 & 31,40 & 29,60 & 233,00 & 207,00 & 103,31 & 105,51 \\
\hline 8 & 32,90 & 24,80 & 32,60 & 31,80 & 238,00 & 208,00 & 111,69 & 114,57 \\
\hline 9 & 33,80 & 23,70 & 34,10 & 33,10 & 252,00 & 206,00 & 92,63 & 93,09 \\
\hline Média & 31,70 & 23,40 & 32,09 & 31,17 & 236,00 & 201,00 & 102,9 & 105,08 \\
\hline
\end{tabular}

* Dados não coletados.

a temperatura ambiente aumenta, a água dos bebedouros é aquecida, o consumo de água aumenta e o de ração diminui. Segundo Xin et al.(2002), quando a temperatura ambiente aumenta de 4,4 para $37,8^{\circ} \mathrm{C}$, a ingestão diária de ração por poedeiras brancas decresce de 130 para 70 g/ave, com redução diária de $1,8 \mathrm{~g} /$ ave para cada $1{ }^{\circ} \mathrm{C}$ de aumento na temperatura e o consumo de água aumenta de 182 para $590 \mathrm{~mL} /$ ave a uma razão de $12,2 \mathrm{~mL} /$ ave a cada $1^{\circ} \mathrm{C}$ de aumento na temperatura ambiente.

Os resultados obtidos nesta pesquisa corroboram também a afirmativa de que, em alta temperatura ambiente, em virtude da necessidade da eliminação do calor corporal, as aves ingerem mais água para atender à demanda do resfriamento evaporativo e diminuem a ingestão de ração (Leeson \& Summers, 2001; Furlan \& Macari, 2002). As maiores médias de temperatura e consumo de água e o menor consumo de ração foram registrados em períodos de maior temperatura ambiente na segunda e nona semanas do experimento.

A temperatura da água não teve correlação com o tipo de bebedouro, logo, a temperatura da água nos dois tipos de bebedouro foi influenciada pelas variações de temperatura ambiente no galpão. Klosowski et al. (2004) também constataram que a temperatura da água nos bebedouros nipple e calha são influenciadas pela temperatura ambiente. De acordo com os pesquisadores, no bebedouro nipple, a água oferecida às aves apresentou temperatura mais elevada, em virtude das características do sistema. A diferença na temperatura da água não diferiu significativamente entre os bebedouros taça e nipple, avaliados nesta pesquisa.

Na análise de correlação, o consumo de água esteve associado $(\mathrm{r}=-0,86)$ ao tipo de bebedouro $(\mathrm{P}<0,05)$, porém, o consumo de ração não apresentou correlação significativa com o tipo de bebedouro. Segundo Leeson \& Summers (2001), o consumo de água está relacionado à ingestão de alimento e fatores que influenciam o consumo de alimento afetam indiretamente a ingestão de água. Os resultados obtidos nesta pesquisa, no entanto, evidenciam que nem sempre as alterações no consumo de água ocorrem na mesma magnitude da ingestão de ração, pois, embora a correlação entre o consumo de água e o de ração e entre o consumo de água e o tipo de bebedouro tenham sido significativas, o consumo de ração não teve correlação significativa com o tipo de bebedouro utilizado. Ramos et al. (1990) avaliaram o uso de bebedouros nipple e taça para poedeiras e verificaram que o tipo de bebedouro utilizado não teve correlação significativa com o consumo de água e de ração. Segundo esses pesquisadores, as variações entre resultados de pesquisas podem estar relacionadas à baixa correlação entre o consumo diário de água e o de ração.

Durante todo o período experimental, foram obtidos valores (Tabela 1) que indicam maior consumo de água pelas aves criadas com bebedouro taça, o que resultou em consumo médio de $35 \mathrm{~mL}$ de água/ave/dia a mais de água. Comparando o uso de bebedouros tipo taça e nipple, Ramos et al. (1990) verificaram que, embora a diferença não tenha sido significativa, as aves criadas com bebedouro nipple consumiram 13,9 mL/ave/dia a mais. Entretanto, Macari (1996) relatou que a substituição do bebedouro tipo calha por bebedouro nipple resultou em menor consumo de água entre as aves criadas com bebedouro nipple.

Segundo Ramos et al. (1990), um fator importante no uso dos sistemas de fornecimento de água para as poedeiras é a posição dos bebedouros nas gaiolas, pois pode interferir diretamente no acesso das aves à água, assim como na quantidade de água ingerida. De acordo com esses pesquisadores, o maior consumo pelas poedeiras criadas com bebedouros nipple pode ser relacionado ao acionamento acidental dos bebedouros durante a movimentação das aves nas gaiolas. Assim, é possível que o desperdício de água tenha contribuído para o maior valor obtido para o 
consumo de água pelas aves criadas com bebedouro taça, o que não significa verdadeiramente maior ingestão de água por estas aves em relação àquelas criadas com bebedouro nipple. No ato de dessedentação das aves criadas com bebedouros taça, as aves costumam molhar as barbelas, portanto, ocorrem dois eventos que ocasionam desperdício e erro na quantidade de água ingerida, uma vez que a água desperdiçada é computada erroneamente como ingerida. $\mathrm{O}$ primeiro evento pode ocorrer quando as aves, ao buscarem a água, mergulham as barbelas nas taças, promovendo o transbordamento da água retida ou da sobra do excessivo acionamento do bebedouro. O segundo ocorre quando as aves levantam a cabeça para deglutir a água e o excesso de água do bico escorre via barbelas e se soma á água retirada pelas barbelas molhadas.

Na avaliação do desempenho (Tabela 2), o consumo de ração não diferiu significativamente entre os tipos de bebedouro. Entretanto, a porcentagem de postura e a massa de ovo produzida foram significativamente maiores entre as aves que receberam água no bebedouro nipple. Esses resultados influenciaram a conversão alimentar ( kg ração/kg de ovo), que foi melhor nas aves criadas com bebedouro nipple.

Os resultados de desempenho obtidos nesta pesquisa diferem, em parte, dos encontrados na literatura. Comparando o uso de bebedouros nipple e taça, Roush \& Mylet (1986) e Roush \& Boggan (1987) observaram menor produção de ovos e pior conversão alimentar ao utilizarem os bebedouros nipple. Redução na produção de ovos também foi constatada por Macari (1996), que alterou o sistema de dessedentação do tipo calha para o tipo nipple. Ramos et al. (1990) verificaram que o uso de bebedouros nipple ou taça não influenciou significativamente $\mathrm{o}$ consumo de ração, a produção de ovos e a conversão alimentar das poedeiras.

Segundo Roush \& Boggan (1987) e Macari (1996), com o uso do bebedouro nipple, pode ocorrer privação parcial de água, o que contribui para menor consumo de água e de ração e, conseqüentemente, para menor produção de ovos

Tabela 2 - Desempenho de poedeiras comerciais criadas com dois tipos de bebedouro

\begin{tabular}{lrrr}
\hline Variável & \multicolumn{2}{c}{ Bebedouro } & \multirow{2}{*}{ CV (\%) } \\
\cline { 2 - 3 } & \multicolumn{1}{c}{ Taça } & \multicolumn{1}{c}{ Nipple } & \\
\hline Consumo de ração (g/ave.dia) & $102,90 \mathrm{a}$ & $105,08 \mathrm{a}$ & 4,00 \\
Percentagem de postura (\%) & $92,80 \mathrm{~b}$ & $97,72 \mathrm{a}$ & 4,17 \\
Massa de ovo (g/ave.dia) & $56,20 \mathrm{~b}$ & $58,90 \mathrm{a}$ & 3,35 \\
Conversão alimentar (kg/kg) & $1,83 \mathrm{~b}$ & $1,78 \mathrm{a}$ & 3,50 \\
\hline
\end{tabular}

Médias nas linhas, seguidas de letras diferentes diferem $(P<0,05)$ estatisticamente pelo teste F. e pior conversão alimentar. Diferentemente do relatado por esses pesquisadores, nesta pesquisa, apesar da menor ingestão de água pelas aves criadas com bebedouros nipple, a quantidade de água ingerida por estas aves foi suficiente para atender às necessidades, visto que não houve prejuízo no desempenho. Considerando que o consumo de água e de ração são correlacionados e que não houve diferença na conversão alimentar das aves submetidas ao uso de bebedouros nipple ou taça, Ramos et al. (1990) concluíram que a privação de água não ocorre com o uso de bebedouro nipple.

Nenhuma das características de qualidade dos ovos foi influenciada pelo tipo de bebedouro. Roush \& Mylet (1986) e Roush \& Boggan (1987) verificaram que o tipo de bebedouro utilizado não influenciou o peso, a porcentagem de casca e os valores de unidades Haugh dos ovos. Entretanto, Roush \& Boggan (1987) observaram que, para um dos bebedouros tipo taça avaliados, os valores de gravidade específica dos ovos foi menor em comparação aos obtidos com o bebedouro nipple. Ramos et al. (1990) constataram que o peso dos ovos das aves criadas com bebedouros taça foi significativamente maior que o das aves criadas com bebedouros nipple.

Nas criações com bebedouro taça, foi obtida concentração de >1100 NMP/100 mL em 100\% das amostras analisadas para coliformes totais e em $67 \%$ daquelas avaliadas quanto às concentrações de coliformes fecais (Tabela 4). Nas criações com bebedouro nipple, nenhuma das amostras coletadas apresentou concentração de coliformes totais ou fecais de $>1100 \mathrm{NMP} / 100 \mathrm{~mL}$. Em 22\% das amostras, a concentração de coliformes fecais foi $<3,0 \mathrm{NMP} / 100 \mathrm{~mL}$.

Os coliformes fecais e totais são os indicadores de contaminação mais usados para monitorar a qualidade sanitária da água. No Brasil, não há legislação específica para o controle de qualidade da água destinada à avicultura, entretanto, recomenda-se que a água destinada à dessedentação das aves seja potável, ou seja, de pureza compatível com as necessidades fisiológicas e sanitárias (Macari, 1997). De acordo com o CONAMA (2005), para

Tabela 3 - Características dos ovos de poedeiras criadas com dois tipos de bebedouro

\begin{tabular}{lccc}
\hline Variável & \multicolumn{2}{c}{ Bebedouro } & \multirow{2}{*}{ CV (\%) } \\
\cline { 2 - 3 } & Taça & Nipple & \\
\hline Peso do ovo (g) & 60,57 & 60,28 & 2,29 \\
Gravidade específica & 1.084 & 1.083 & 0,15 \\
Porcentagem de casca (\%) & 9,14 & 9,15 & 3,45 \\
\hline
\end{tabular}


Tabela 4 - Qualidade bacteriológica da água fornecida para poedeiras comerciais em bebedouros do tipo nipple e do tipo taça

\begin{tabular}{lcc}
\hline & \multicolumn{2}{c}{ Bebedouro } \\
\cline { 2 - 3 } & Taça & Nipple \\
\hline Coliformes totais $(\mathrm{NMP} / 100 \mathrm{~mL})$ & $>1100$ & 93 \\
Máximo & $>1100$ & $<3$ \\
Mínimo & 0 & $2 *(22 \%)$ \\
$\mathrm{N}^{\circ}$ de amostras $<3$ & $9 *(100 \%)$ & 0 \\
$\mathrm{~N}^{\circ}$ de amostras $>1100$ & $>1100$ & 93 \\
Coliformes fecais (NMP/100 mL) & 23 & $<3$ \\
Máximo & 0 & $2 *(22 \%)$ \\
Mínimo & $6 *(67 \%)$ & 0 \\
$\mathrm{~N}^{\circ}$ de amostras $<3$ & N $^{\circ}$ de amostras $>1100$ & \\
\hline
\end{tabular}

* Diferente em relação ao outro tratamento de acordo com o teste do quiquadrado (5\%).

animais em confinamento, o limite de 1.000 coliformes termotolerantes e 4.000 coliformes totais não deve ser excedido, entretanto, as aves criadas atualmente, de linhagem geneticamente desenvolvida, são mais sensíveis e não toleram essas concentrações. A portaria 518/2004 do Ministério da Saúde (Brasil, 2005) considera potável a água com ausência de coliformes termotolerantes e totais em amostras de até $100 \mathrm{~mL}$. Curtis et al. (2001) recomendaram que, para aves de postura, o limite máximo permitido para coliformes total e fecal em água de dessedentação seja de 100 e 50/mL de água, respectivamente.

De acordo com os resultados obtidos, a presença de coliformes não depende do tipo de bebedouro utilizado, no entanto, a concentração e o risco de problemas é maior para aves criadas com bebedouro taça, cuja contagem bacteriológica foi superior aos níveis recomendados para água potável. Amaral et al. (1999) e Valias \& Silva (2001) observaram que o tipo de bebedouro influenciou a qualidade da água e ressaltaram que o bebedouro nipple protegeu melhor a água da contaminação bacteriológica. A água apresentou menor índice de contaminação por coliformes totais e fecais em comparação à água do bebedouro pendular.

Comparando bebedouros taça e nipple para aves de postura, Amaral et al. (2001) verificaram maior grau de contaminação na água de dessedentação de bebedouros tipo taça e ressaltaram também que as aves criadas com bebedouro tipo taça, além de receberem água de qualidade higiênico-sanitária inferior, estiveram sujeitas à infecção por agentes patogênicos de origem entérica. Segundo Amaral (2004), a precocidade das linhagens das aves atualmente no mercado também as tornou menos resistentes e mais susceptíveis às infecções, principalmente àquelas causadas por patógenos de origem intestinal, que podem estar presentes na água e na contaminação fecal. Dessa forma, é possível que a maior produção de ovos e a melhor conversão alimentar observada para as aves criadas com bebedouro nipple estejam relacionadas à melhor qualidade da água, pois, com a menor contaminação bacteriológica neste tipo de bebedouro, o desafio intestinal pode ter sido menor.

\section{Conclusões}

O tipo de bebedouro utilizado nas criações de poedeiras comerciais influencia o desempenho e a qualidade da água oferecida. O bebedouro tipo nipple mantém a qualidade microbiológica da água e, conseqüentemente, favorece o desempenho das aves.

\section{Literatura Citada}

AMARAL, L.A.; ROSSI JR., O.D.; CARDOSO, V. Qualidade higiênico-sanitária da água de bebedouros pendular e nipple utilizados na criação de frangos de corte. Revista Brasileira de Ciência Avícola, v.1, n.2, p.145-148, 1999.

AMARAL, L.A.; NADER FILHO, A.; ISA, H. et al. Qualidade higiênico sanitária e demanda de cloro da água de dessedentação de galinhas de postura coletadas em bebedouros tipo taça e nipple. Revista Brasileira de Ciência Avícola, v.3, n.3, p.249-255, 2001.

AMARAL, L.A. Drinking water as a risk factor to poultry health. Revista Brasileira de Ciência Avícola, v.6, n.4, p.191-194, 2004.

BARROS, L.S.S.; AMARAL, L.A.; ROSSI JR., O.D. Aspectos microbiológicos e demanda de cloro de amostras de água de dessedentação de frangos de corte coletadas em bebedouros pendulares. Revista Brasileira de Ciência Avícola, v.3, n.2, p.193-198, 2001.

BRASIL. Ministério da Agricultura Pecuária e Abastecimento. Instrução Normativa $n^{\circ} 62$ de 26/08/2003. Seção 1, p.14. Estabelece os Métodos Analíticos e Oficiais para Análises Bacteriológicas para Controle dos Produtos de Origem Animal e água. Diário Oficial [da] República Federativa do Brasil, Brasília, DF, 18 de Setembro 2003.

BRASIL. Ministério da Saúde. Secretaria de Vigilância em Saúde. Coordenação-Geral de Vigilância em Saúde Ambiental. Portaria MS n. ${ }^{\circ}$ 518/2004 / Ministério da Saúde, Secretaria de Vigilância em Saúde, Coordenação-Geral de Vigilância em Saúde Ambiental - (Série E. Legislação em Saúde) Brasília: Editora do Ministério da Saúde, 1.ed. 2005. 28p.

CONAMA. Ministério do Meio Ambiente. Conselho Nacional do Meio Ambiente. Resolução № 357, DE 17 DE MARÇO DE 2005. Disponível em: <http://www.mma.gov.br/port/conama/ res/res05/res35705.pdf $>$. Data de acesso: 29/4/2008.

CURTIS, L.; HAIRSTON, J.; DONALD, J. Factores clave del agua en la producción de pollos. Indústria Avícola, p.26-31, julho, 2001.

FAIRCHILD, B.D.; RITZ, C.W. Poultry drinking water primer. University of Georgia, 2006. (Cooperative Extension Bulletin, 1301).

FURLAN, R.L.; MACARI, M. Termorregulação: fisiologia aviária aplicada a frangos de corte. Jaboticabal. FUNEP/UNESP, 2002. $375 p$.

GAMA, N.M.S.Q. Qualidade química e bacteriológica da água utilizada em granjas produtoras de ovos. Jaboticabal: Universidade Estadual Paulista, 2005. 87p. Tese (Doutorado 
em Medicina Veterinária) - Universidade Estadual Paulista, 2005.

GERNAT, A.G.; ADAMS, A.W. Effect of number and location of nipple waterers and cage shape on the performance of caged layers. Poultry Science, v.69, p.2086-2091, 1990.

GERNAT, A.G.; ADAMS, A.W. Effect of number of hens per nipple waterer on the performance of several strains of layers in cages. Poultry Science, v.71, p.1292-1295, 1992.

KLOSOWSKI, E.S.; CAMPOS, A.T.; GASPARINO, E. et al. Temperatura da água em bebedouros utilizados em instalações para aves de postura. Engenharia Agrícola, v.24, n.3, p.493-500, 2004.

KOELKEBECK, K.W.; MCKEE, J.S.; HARRISON, P.C. et al. Performance of laying hens provided water from two sources. Journal of Applied Poultry Science Research, v.8, p.374-379, 1999.

LEESON, S.; SUMMERS, J.D. Commercial poultry nutrition. 2.ed. Guelph: University Books, 1997. 101p.

LEESON, S.; SUMMERS, J.D. Nutrition of chicken. 4.ed. Guelph. University Books, 2001. 415p.

MACARI, M. Água na avicultura industrial. Jaboticabal: FUNEP, 1996. 128p.

MACARI, M. Qualidade da água e bebedouros para frangos de corte: tipos, vantagens e desvantagens. In: CONFERÊNCIA APINCO‘97 DE CIÊNCIA E TECNOLOGIA AVÍCOLAS, São Paulo. Anais... Campinas: Fundação Apinco de Ciência e Tecnologia Avícolas, 1997. p.121-143.
RAMOS, N.C.; GERNAT, A.G.; ADAMS, W. Effects of cage, shape, age at housing and types of rearing and layer waterers on the productivity of layers. Poultry Science, v.69, p.217-223, 1990.

ROUSH, W.B.; MYLET, M. Effect of water softening watering devices, and dietary salt level on the performance of caged Single Comb White Leghorn laying hens. Poultry Science, v.65, p.1866-1871, 1986.

ROUSH, W.B.; BOGGAN, G.D. Effect of watering devices on performance during pullet-rearing and cage-laying phases of Single Comb White Leghorn laying hens. Poultry Science, v.66. p.1431-1436, 1987.

STATISTICAL ANALYSIS SYSTEM - SAS. System for Microsoft Windows. release 8.2. Cary: SAS Institute, 2001. (CD-ROM).

TABLER, G.T. Water intake: a good measure of broiler performance. Avian Advise, v.5, n.3, p.7-9, 2003.

VALIAS, A.P.G.S.; SILVA, E.N. Estudo comparativo de sistemas de bebedouros na qualidade microbiológica da água consumida por frangos de corte. Revista Brasileira de Ciência Avícola, v.3, n.1, p.83-89, 2001.

VOHRA, N.P. Water quality for poultry use. Feedstuffs, v.7, p.24$25,1980$.

XIN, H.; GATES, R.S.; PUMA, M.C. et al. Drinking water temperature effects on laying hens subjected to warm cyclic environments. Poultry Science, v.81, n.8, p.608-617, 2002. 